\title{
DEPRESSÃO INFANTIL: ENSINO-APRENDIZAGEM A PARTIR DE UMA EXPERIÊNCIA ESCOLAR NO ESPÍRITO SANTO
}

\author{
Maria das Graças Gonçalves Vieira Guerra* \\ Fernanda Matos de Moura Almeida** \\ Danielle Borges Afonso***
}

RESUMO: O objetivo deste artigo foi analisar como a equipe pedagógica e os pais dos alunos do $1^{\circ}$ ao $3^{\circ}$ ano do Ensino Fundamental da Escola Estadual Henrique Coutinho, em Iúna (ES), que lidam com a questão da Depressão Infantil, se eles tinham conhecimento sobre a mesma, e como eles identificam os sintomas de Depressão nas crianças. A pesquisa é descritiva, bibliográfica, de levantamento de dados e de observação. Para coletar informações foram utilizados formulários para os alunos e questionário para os pais; e equipe pedagógica. Os resultados demonstram que os pais e a equipe pedagógica têm, mesmo que moderado, conhecimento sobre Depressão Infantil. Observou-se também a necessidade de debate sobre o tema entre os pais e a escola, podendo assim reduzir o índice de crianças com sintomatologia depressiva. Portanto, infere-se que a escola e os pais precisam estar em constante sintonia para buscar conhecimentos em relação à Depressão Infantil.

PALAVRAS-CHAVE: Depressão Infantil; Ensino-Aprendizagem; Escola.

\section{DEPRESSION IN CHILDHOOD: TEACHING-LEARNING FROM A SCHOOL EXPERIENCE IN THE STATE OF ESPÍRITO SANTO, BRAZIL}

ABSTRACT: Current article analyzes the manner the pedagogical team and parents of students of Years 1 to 3 of the State School Henrique Coutinho, in Iúna ES Brazil, deal with depression in childhood. It also discusses whether they had any knowledge on the matter and how they identified its symptoms in children. The descriptive

\footnotetext{
Pós-Doutoranda pela Universidade do Porto - Portugal. Doutora em Educação pela Universidade Federal da Paraíba (UFPB). Docente Associada I do Centro de Educação da Universidade Federal da Paraíba e docente dos quadros permanentes dos Programas de Pós-Graduação em Educação (PPGE) e de Políticas Públicas, Gestão e Avaliação da Educação Superior (MPPGAV) da UFPB, Brasil. E-mail: gracinhavieira@yahoo.com.br

** Docente e Coordenadora na Faculdades Doctum Iúna (ES) nos cursos de graduação e pós-graduação. Docente e Coordenadora na Faculdade de Ciência e Educação do Caparaó (FACEC) nos curso de Ciências Contábeis e Administração. Brasil.

*** Discente do curso de Pedagogia da Faculdade Doctum, Brasil.
} 
research surveys data and observations. Forms were given to students, whilst parents and pedagogical team received a questionnaire. Results show that parents and the pedagogical team have only a slight knowledge on depression in childhood. Debates on the theme between parents and school authorizes should be enhanced to reduce the index of children with symptoms of depression. Results show that school and parents should be fine-tuned on information on child depression.

KEY WORDS: Depression in childhood; Teaching-learning process; School.

\section{INTRODUÇÃO}

A pedagogia é a ciência que tem a educação como objeto de estudo (LIBÂNEO, 2001) e, para o mesmo autor, a sociologia, a psicologia, a economia, entre outras ciências, também podem e têm se ocupado com problemas educativos, tendo em vista que é a pedagogia a responsável por integrar os enfoques das diversas ciências (sociologia, psicologia etc.) em função de uma aproximação global e intencionalmente dirigida aos problemas educativos.

A depressão é de natureza multicausal, o que torna indispensável uma avaliação que aprecie a história familiar, que envolve os fatores genéticos e antecedentes pessoais e também a verificação de condições médicas e ambientais associadas (ASSUMPÇÃO JÚNIOR, 2014).

A depressão infantil, de acordo com Huttel et al. (2011), acarreta prejuízos a nível físico, cognitivo, psicomotor e psicossocial no desenvolvimento da criança. Diante disso, a família e o grupo que a criança está inserida também são afetados (CALDERARO; CARVALHO, 2005).

A depressão na infância vem chamando a atenção de muitos profissionais que atuam com crianças. Essa patologia, no entanto, não é frequentemente reconhecida, uma vez que os sintomas diferem dos apresentados pelos adultos, dificultando o diagnóstico (SCIVOLETTO; TARELHO, 2002).

Segundo Loiola (2009), a depressão afeta 01 em cada 20 crianças abaixo dos 10 anos de idade, ainda ressalta que a depressão infantil pode afetar o rendimento escolar, o desenvolvimento emocional normal e a estabilidade de toda família. 
A falta de informações de pais e professores sobre a depressão infantil pode contribuir para aumentar as dificuldades dos alunos e causar inúmeras sequelas emocionais no futuro. É evidente que família e educadores não estão preparados para fazer um diagnóstico na criança. Cabe ressaltar que nem é esse o papel dos mesmos. No entanto, um olhar mais atento a essas crianças permite que sejam reconhecidas mais cedo e encaminhadas para um diagnóstico mais cuidadoso associado à intervenção necessária (CRUVINEL, 2003, p. 29).

A escolha do tema se deu pela importância do mesmo, e por perceber que este problema afeta cada vez mais os alunos, que por fim não conseguem alcançar a aprendizagem e tendem a ter comportamentos inadequados.

O tema abordado chama a atenção, não só dos profissionais atuantes na área educacional, mas também de toda sociedade sujeita a passar por tal situação.

O objetivo da pesquisa é de investigar como os pais e a equipe pedagógica lidam com a questão da Depressão Infantil na Escola Estadual de Ensino Fundamental e Médio Henrique Coutinho, na cidade de Iúna (ES).

A presente pesquisa pretende contribuir para um aprofundamento temático, podendo ser usada como nova fonte bibliográfica para futuras pesquisas e para demonstrar a importância de se conhecer a Depressão Infantil.

\section{DEPRESSÃO INFANTIL}

A depressão é caracterizada como um transtorno de humor, porém, abrange fatores cognitivos, comportamentais, fisiológicos, sociais, econômicos e religiosos, entre outros, estando presente em diversos distúrbios emocionais, pode coexistir juntamente com outros estados emocionais, e aparecer como um sintoma de determinada doença (HOLMES, 1997).

A depressão é um transtorno de humor, que se manifesta através de um conjunto de sintomas, que alteram o pensamento, comportamento, sentimentos e fisiologia da pessoa deprimida, durante um período significativo de tempo, sendo no mínimo de duas semanas (MILLER, 2003).

Para Cruvinel e Boruchovitch (2003) a depressão é um transtorno que tem marcado inúmeras pessoas e tem levado muitos ao sofrimento e desespero, ela não procura raça, crença ou idade, está presente em todos os lugares do mundo, acome- 
tendo qualquer pessoa sem exceção.

De acordo com Calderano e Carvalho (2005) a depressão em crianças existe sim, tendo em vista que as crianças também se angustiam frente às dificuldades da vida e podem apresentar sofrimento existencial, porém, elas estão menos preparadas que os adultos para suportar as pressões e as frustrações.

Castro Neto (2002) salienta que a depressão tem efeitos sérios e de grande repercussão na vida de uma criança, prejudicando o desempenho escolar e a interação com amigos e familiares.

Os sintomas de depressão podem se manifestar de diferentes formas no ambiente escolar. O professor deve estar alerto a alguns sinais indicativos e pensar na possibilidade de depressão diante de uma criança que revela uma expressão de tristeza, ou mudança no nível de atividade, diminuição no rendimento escolar, fracasso em terminar suas tarefas escolares, isolamento social, agressividade ou verbalizações como: "Eu não posso fazer isso" (LIVINGSTON, 1985).

Cohen e Marcelli (2009) dizem que a criança que é diagnosticada com depressão, apresenta algumas características peculiares, como desaceleração psicomotora e inibição motriz, rosto com pouca expressão, pouca mobilidade e apresenta-se pouco sorridente.

Embora na maioria das crianças os sintomas da depressão sejam atípicos, algumas podem apresentar sintomas clássicos da depressão, tais como: tristeza, ansiedade, expectativa pessimista, mudanças no hábito alimentar e no sono ou, por outro lado, problemas físicos, como dores inespecíficas, fraqueza, tonturas, mal-estar geral (BALLONE, 2004).

Segundo Lima, Garcia e Figueiredo (2005) entre os fatores mais comuns relacionados à depressão em crianças predominam: a hiperatividade, sentimentos de rejeição, agressividade e isolamento.

Anjos e Fonseca (2002) ressaltam que, com relação ao tratamento, o ideal seriam estratégias reforçadoras positivas, psicoterapia individual com a criança, com a família e orientação na escola.

É necessário entender que; somente um profissional especializado é capaz de realizar o diagnóstico, entretanto o professor pode e deve estar atento nas mudanças de comportamento dos alunos; caso existam suspeitas, o caminho é conversar com os pais e/ou responsáveis para uma possível solução, deve-se orientar 
os familiares a procurar um psicólogo para que assim ele desenvolva o tratamento adequado de acordo com a avaliação e o diagnóstico (CRUVINEL; BORUCHOVITCH, 2004).

\subsection{DEPRESSÃO INFANTIL NA ESCOLA}

Segundo Fonseca et al. (1988) os problemas psicológicos infantis não devem ser avaliados como um fenômeno transitório e sem gravidade, uma vez que essas dificuldades podem evidenciar uma grande estabilidade temporal, e ainda auxiliam afetando negativamente o processo de desenvolvimento da criança.

É necessário olhar o aluno em sua totalidade, considerando suas características de personalidade, seu estado emocional, suas crenças e cognições frente à aprendizagem (FIERRO, 1996).

De acordo com Cruvinel e Boruchovitch (2004) a depressão infantil deixa de ser um problema individual ou familiar, e passa a ser um problema escolar, pois a escola tem um papel essencial na identificação e no auxílio para o encaminhamento a profissionais qualificados para o tratamento dos sintomas depressivos, é de extrema importância que os professores conheçam esse transtorno de humor.

Desde que o transtorno depressivo em crianças e adolescentes na idade escolar envolva sintomatologia que interfira nas habilidades de aprendizagem, a educação deve ser instruída quanto às intervenções pedagógicas a partir dos conceitos de saúde e patologia física e mental, oportunizando práticas educacionais como atividades de promoção de saúde. É importante que as escolas reconheçam que a depressão pode se tornar um problema grave, vindo a gerar alterações no funcionamento social e acadêmico de seus alunos (BAUER, 2007, p. 21)

Miller (2003) afirma que há pessoas na escola, como professores, orientadores e psicopedagogos, que estando bem preparados podem fornecer apoio, orientação, afeto e preocupação com a criança, encorajando-a a ser independente e contribuir para reversão do quadro depressivo.

Para Bahls (2004) são os professores que geralmente percebem primeiro os sintomas de depressão nas crianças, pois um dos primeiros indícios é a queda no rendimento escolar, onde o declínio no desempenho escolar deve-se à fraca concen- 
tração ou à falta de interesse, próprios do quadro depressivo.

Embora o diagnóstico de depressão infantil não seja nem deva ser papel dos educadores, a escola e o professor desempenham uma função extremamente relevante no reconhecimento dos sintomas de depressão, uma vez que a presença da depressão de fato interfere no rendimento do aluno e também tende a influir no emprego de estratégias de aprendizagem. É possível que a queda no rendimento escolar possa ser utilizada como um sinal para os pais e professores de que algo não vai bem com aquela criança e esta pode estar vivenciando sintomas depressivos (CRUVINEL; BORUCHOVITCH, 2003, p. 376).

É fundamental que os professores se mantenham atualizados sobre os principais problemas e conflitos enfrentados por crianças com quem eles trabalham no dia e como são as intervenções para melhor solucionar os problemas apresentados. Por isso, é importante o professor ter conhecimento (NUNES; AZAMBUJA, 2004).

$\mathrm{Na}$ fase escolar, o cansaço, a dificuldade de concentração, as alterações da memória, a astenia e a adinamia são as complicações da depressão infantil, que afetam muito o rendimento escolar e a aprendizagem (BALLONE, 2004).

A baixa motivação é uma das principais razões para as dificuldades escolares, e ao pobre desempenho acadêmico, se manifesta como falta de interesse, pois, na criança deprimida a ação e a expressão estão alteradas, inibidas, e suas repercussões são notadas na indiferença, no desinteresse tanto por atividades habituais de rotina, como nas atividades escolares e brincadeiras (MAJ; SARTORIUS, 2005).

Sommerhalder e Stela (2001) descrevem que, na sala de aula, a criança com sintomas de depressão normalmente mostra-se desinteressada pelas atividades, apresenta dificuldade em permanecer atenta nas tarefas e esse comportamento interfere de forma negativa na aprendizagem dessas crianças. As escolas devem se adequar à realidade e aos avanços culturais, orientando e atualizando os pais com leituras adequadas, palestras e esclarecimentos sobre os problemas psicológicos que afetam o desenvolvimento dos filhos (TIBA, 2012).

É preciso que os educadores aprendam a lidar, reconhecer e identificar sintomas depressivos em seus alunos para assim ajudá-los no sentido de reduzir as consequências negativas da depressão na assimilação de conhecimentos (CRUVINEL; BORUCHOVITCH, 2004). 
Miller (2003) correlaciona o trabalho pedagógico como auxiliador dos pais e profissionais no diagnóstico da depressão, pois este trabalho em conjunto garante ajuda, serviços e sucesso.

\section{METODOLOGIA DA PESQUISA}

A pesquisa teve como público-alvo 101 alunos matriculados nas turmas do $1^{\circ}$ ao $3^{\circ}$ ano do ensino fundamental, sendo eles 25 do $1^{\circ}$ ano, 25 do $2^{\circ}$ do ano, 25 do $3^{\circ}$ ano (1) e 26 do $3^{\circ}$ ano (2); 08 profissionais da equipe pedagógica, onde se enquadram 04 professores, 02 coordenadores, 01 pedagogo e 01 diretor e ainda 99 pais dos alunos do $1^{\circ}$ ao $3^{\circ}$ ano da Escola Estadual de Ensino Fundamental e Médio Henrique Coutinho do município de Iúna (ES). Vale ressaltar que em duas turmas há alunos gêmeos, por esse motivo se justifica a quantidade de pais.

Esta pesquisa se classifica como descritiva. A pesquisa descritiva observa, registra e analisa os fenômenos, sem entrar no mérito de seu conteúdo (OLIVEIRA, 2002).

Marconi e Lakatos (2003) e Oliveira (2002) evidenciam que a pesquisa descritiva consiste em investigações de pesquisa empírica, cuja finalidade é a análise das características de fatos ou fenômenos, avaliação de programas ou isolamento de variáveis principais ou chave. Ainda segundo os autores, para que o pesquisador consiga alcançar um melhor entendimento sobre o que influencia no fenômeno, o método descritivo será o mais adequado.

A pesquisa é bibliográfica, pois foram utilizados vários materiais já elaborados como livros, jornais, artigos científicos e sites especializados.

Esta pesquisa se classifica ainda como de levantamento de dados, pois com a colaboração das informações transmitidas pela equipe pedagógica, pais e alunos da escola pesquisada, procurou-se atender os objetivos propostos, proporcionando à pesquisadora o conhecimento da realidade da escola pesquisada.

A pesquisa é de observação pelo fato de as pesquisadoras terem observado a reação dos alunos diante das perguntas propostas no formulário, com intuito de complementar e cumprir os objetivos da referida pesquisa. 
A coleta dos dados para realização da pesquisa foi feita por meio de formulário e questionário. Para que o objetivo da pesquisa fosse alcançado, foi realizado o pré-teste, com intuito de refinar o instrumento de coleta de dados. O pré-teste foi aplicado para $10 \%$ da população que se pretendia pesquisar, foram necessários alguns ajustes para que a pesquisa fosse realizada.

Marconi e Lakatos (2002); dizem que essa é a fase da pesquisa onde é feita a aplicação de instrumentos elaborados e técnicas selecionadas.

As pesquisadoras optaram por entrevistar a equipe pedagógica da Escola Estadual Henrique Coutinho, os pais dos alunos de $1^{\circ}, 2^{\circ}$ e $3^{\circ}$ ano do ensino fundamental, bem como os alunos matriculados nestas turmas.

Os questionários e formulários foram elaborados e aplicados pelas pesquisadoras em setembro de 2015 na própria escola. Para que os pais participassem da pesquisa, os questionários foram grampeados no caderno das crianças, pelas pesquisadoras, que retornaram na escola para buscar as respostas.

\section{ANÁLISE E DISCUSSÃO DOS RESULTADOS}

No geral pode-se observar que, fazendo a média entre todos os respondentes, quanto ao gênero 52\% são do sexo masculino e 48\% são do sexo feminino.

Quando perguntado às crianças se estas se sentem felizes, obteve-se o seguinte resultado: no $1^{\circ}$ ano $96 \%$ das crianças são felizes, enquanto $4 \%$ não são felizes, no $2^{\circ}, 3^{\circ}$ ano (1) e $3^{\circ}$ ano (2), $100 \%$ são felizes.

Streck (2004) afirma que a ocupação principal das crianças deve ser, acima de qualquer coisa, brincar e ser feliz. Bahls (2004) afirma que a depressão em crianças com idade escolar é frequente e a expressão de humor depressivo manifesta-se através de queixas de tristeza e tédio.

Observa-se que embora seja mínimo o percentual de crianças que se sentem tristes, é necessário que sejam observadas para um possível encaminhamento aos profissionais indicados.

Perguntou-se às crianças se, de maneira geral, as coisas davam certo para elas e notou-se que a maioria das crianças acha que tudo dá certo para elas, mas no 
$1^{\circ}$ ano $35 \%$ das crianças acham que isso não acontece sempre, seguidos de $33 \%$ no $2^{\circ}$ ano, $20 \%$ no $3^{\circ}$ ano (1) e $15 \%$ no $3^{\circ}$ ano (2).

Quando perguntado às crianças sobre: gostar de estudar, gostar de fazer atividades, ou seja, gostar de ir para a escola e se elas se sentem bem fazendo isso, o Gráfico 01 revela os resultados em percentuais.

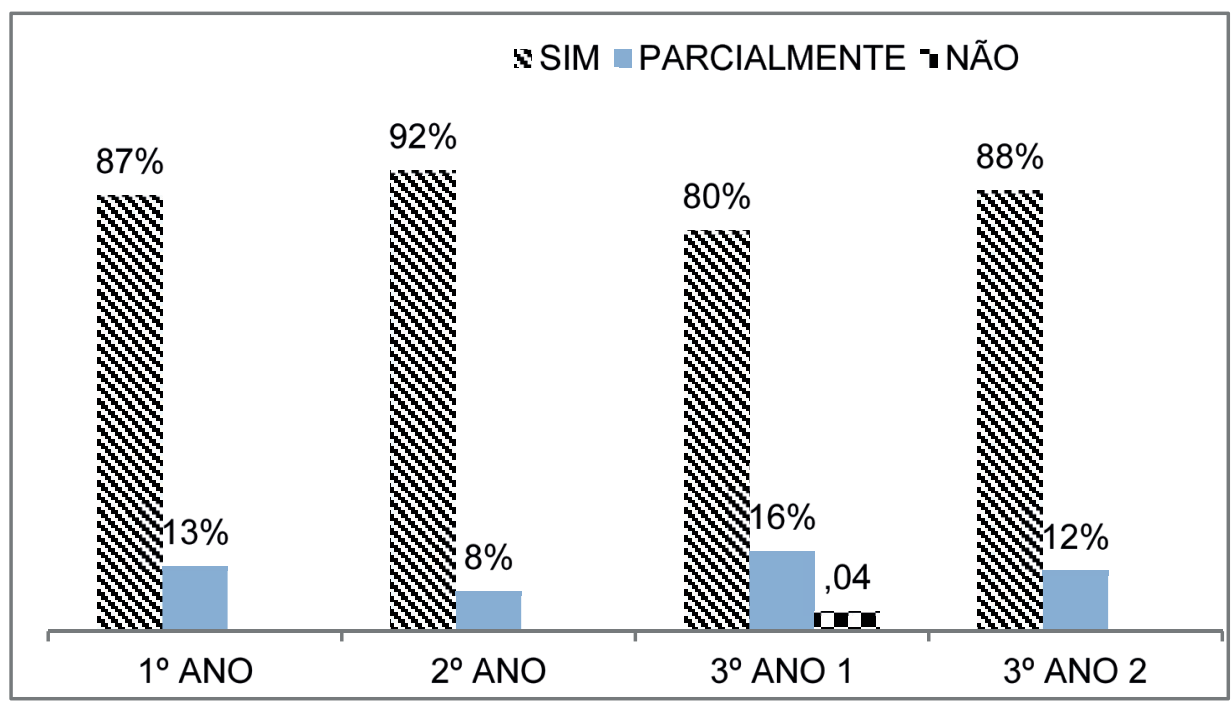

Gráfico 1. Você gosta de estudar e fazer atividades? Fonte: Dados da pesquisa, 2015.

O Gráfico 01 deixa claro que quanto aos estudos, a maioria das crianças gostant de estudar. No $3^{\circ}$ ano (1) $04 \%$ das crianças não gostam de estudar e fazer as atividades. Os percentuais medianos foram $16 \%$ do $3^{\circ}$ ano (1) e $13 \%$ do $1^{\circ}$ ano.

Lafer et al. (2000) afirmam que a falta de interesse ou de motivação nos estudos depende da intensidade da depressão, e defendem que a queda do rendimento escolar pode refletir na queda da atenção, motivação e hipersensibilidade.

Observa-se que a maioria das crianças entrevistadas gosta de estar na escola, de estudar e se divertem fazendo isso, mas ainda assim há uma pequena minoria (04\%) que não gosta, ou não sentem prazer nos estudos.

As crianças que deram um parecer negativo ou parcial às afirmações; relataram que na maioria das vezes não sentem vontade de ir à escola porque têm 
preguiça ou porque não gostam de fazer as atividades, por isso acham chato e ficam desmotivadas. Outras disseram que gostam de ficar em casa para ver desenhos.

Completando, Sommerhalder e Stela (2001) descrevem que, na criança deprimida, as funções cognitivas como atenção, concentração, memória e raciocínio encontram-se alteradas, o que interfere no desempenho escolar, uma vez que, na sala de aula, as crianças com sintomas de depressão normalmente mostram-se desinteressadas pelas atividades, apresentam dificuldades em permanecer atentas nas tarefas, resultando em um comportamento que interfere de forma negativa na aprendizagem dos mesmos.

Nesta pesquisa não se observou o cenário relatado pelos autores acima, mas, ainda assim, pais e professores devem ficar atentos.

O Gráfico 02 relata como as crianças se sentem no dia a dia, se elas se cansam com facilidade ou se são bem-dispostas.

\section{న SIM $\square$ PARCIALMENTE INÃO}

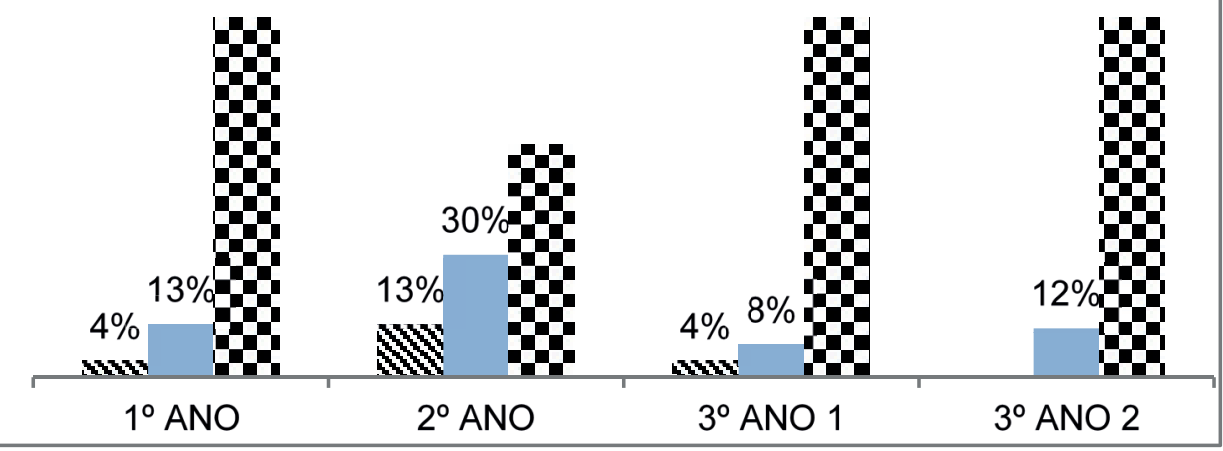

Gráfico 2. Você se sente cansado? Fonte: Dados da pesquisa, 2015.

Analisando o Gráfico 02 percebe-se que a maioria das crianças se sente dispostas, no $2^{\circ}$ ano $30 \%$ se sentem cansadas às vezes e $13 \%$ estão sempre indispostas.

É preciso ressaltar a necessidade de atenção tanto da escola quanto da família das crianças do $2^{\circ}$ ano que apresentaram percentual preocupante de indisposição. 
Em relação à alimentação das crianças, percebeu-se que a maioria das crianças se alimenta corretamente, no $2^{\circ}$ ano $17 \%$ das crianças não se alimentam como deveriam, seguidas de $13 \%$ do $1^{\circ}$ ano, $12 \%$ do $3^{\circ}$ ano (1) e $08 \%$ do $3^{\circ}$ ano (2).

Quanto à qualidade do sono, observou-se que quando perguntados se dormiam bem, a maioria das crianças disse que sim, apenas no $1^{\circ}$ ano $5 \%$ das crianças não dormem bem.

Segundo Scivoletto e Tarelho (2002) os sintomas da Depressão Infantil manifestam-se muitas vezes de forma mascarada, incluindo distúrbios do sono e alimentação.

A maioria das queixas das crianças que não dormiam tão bem quanto deveriam; eram os pesadelos, as crianças relataram que às vezes ficavam acordados para não terem sonhos ruins novamente. O percentual destes respondentes não foi tão relevante mediante as respostas positivas, mas considerando as respostas medianas, $06 \%$ do $1^{\circ}$ ano, $08 \%$ do $2^{\circ}, 04 \%$ do $3^{\circ}$ ano (1) e $08 \%$ do $3^{\circ}$ ano (2) disseram dormir parcialmente bem; então, entende-se que este ponto merece atenção dos pais e da escola.

De forma geral, as crianças de todas as turmas pesquisadas gostam de estar acompanhadas e ter alguém por perto. No $2^{\circ}$ ano $13 \%$ das crianças gostam parcialmente e no $3^{\circ}$ ano (1) $12 \%$.

Percebe-se que a maioria das crianças entrevistadas; gosta de estar próxima às pessoas, não correndo risco de deteriorar o relacionamento com a família e amigos conforme citam Lafer et al. Logo, esta questão especificamente não retrata um perfil depressivo nas crianças.

Quanto aos estudos, a maioria das crianças gosta de estudar. No $3^{\circ}$ ano (1) $04 \%$ das crianças não gostam de estudar e fazer as atividades. Os percentuais medianos foram $16 \%$ do $3^{\circ}$ ano (1) e $13 \%$ do $1^{\circ}$ ano.

Observa-se que a maioria das crianças entrevistadas gosta de estar na escola, de estudar e se divertem fazendo isso, mas ainda assim há uma pequena minoria (04\%) que não gosta, ou não sentem prazer nos estudos.

O Gráfico 03 mostra como é o relacionamento das crianças com sua família. 


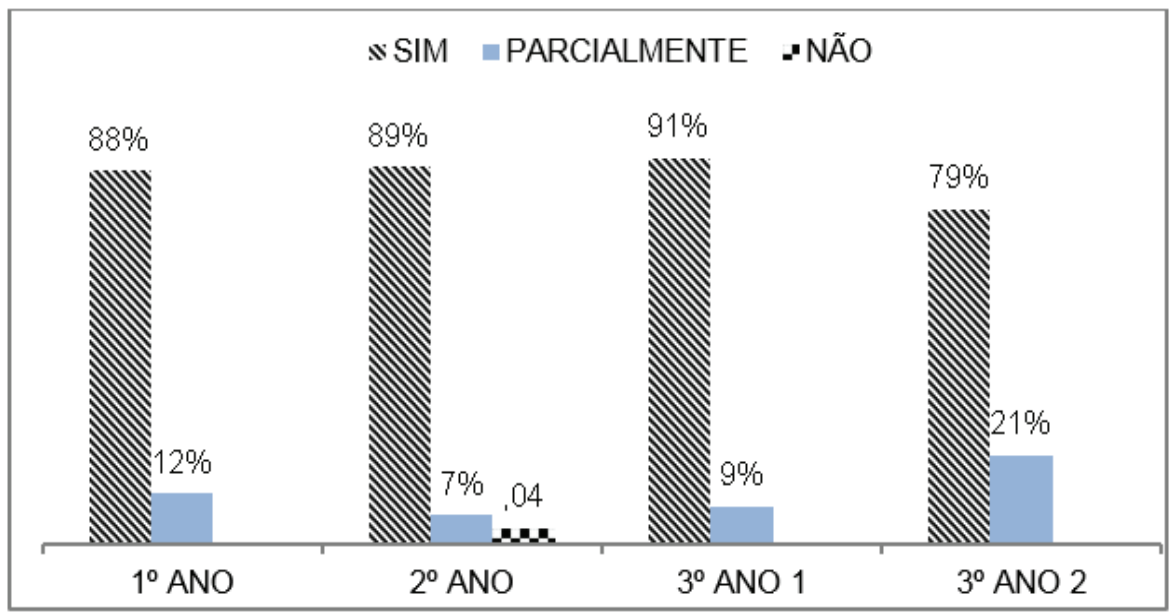

Gráfico 3. Você se relaciona bem com sua família? Fonte: Dados da pesquisa, 2015.

A maioria das crianças se relaciona bem com sua família, no $3^{\circ}$ ano (2) $21 \%$ das crianças se relacionam parcialmente bem, e no $2^{\circ}$ ano $04 \%$ das crianças não se relacionam bem com sua família.

Ao perguntar se as crianças se relacionam bem com suas famílias, algumas ficaram receosas em responder. Observa-se que a maioria respondeu que tem um bom relacionamento com a família, mas é preocupante a relativa minoria que respondeu parcialmente ou que não tem um bom relacionamento familiar.

As crianças que responderam parcialmente, ou que não convivem bem com a família, se queixaram de desleixo dos pais, falta de diálogo, brigas familiares e falta de atenção com eles.

Quanto ao perfil dos componentes da equipe pedagógica identificou-se que $100 \%$ da equipe pedagógica são do sexo feminino, com idade ente 31 a 40 anos (42\%), são pós-graduados (100\%) e atuam há mais de 15 anos na área educacional (57\%).

Com a pesquisa identificou-se que $64 \%$ dos respondentes são mães, com idade entre 31 a 40 anos (38\%), casadas (68\%) e possuem o ensino médio completo (36\%).

Foi questionado aos respondentes qual era o conceito de Depressão. O Gráfico 04 demonstra os resultados. 


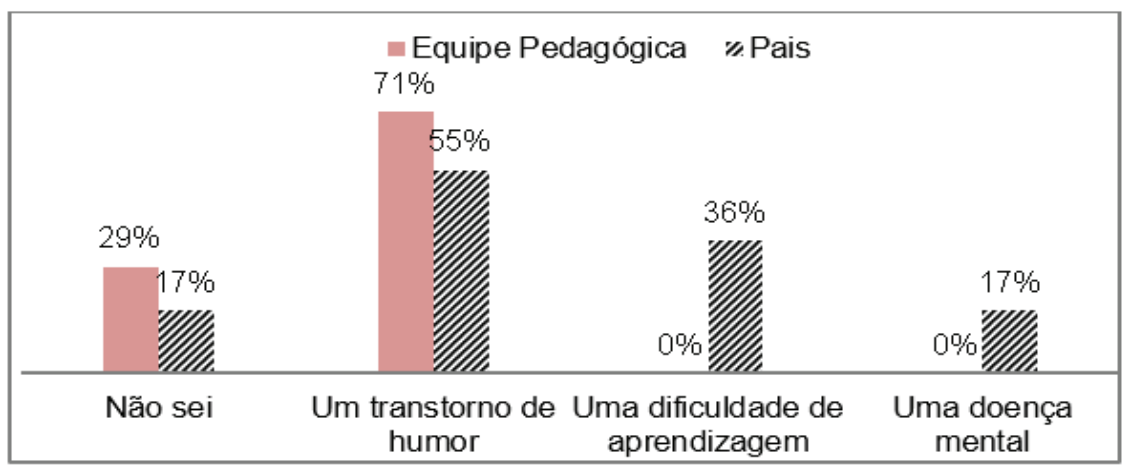

Gráfico 4. Conceito de Depressão Infantil segundo os respondentes Fonte: Dados da pesquisa, 2015.

Um total de $71 \%$ da equipe pedagógica e $55 \%$ dos pais responderam que a Depressão é um transtorno de humor.

Segundo Miller (2003) a Depressão é um transtorno de humor que se manifesta através de um conjunto de sintomas.

A dificuldade na aprendizagem é outro conceito de depressão defendido por Sommerhalder e Stela (2001).

É importante destacar que tanto os pais quanto os professores em sua maioria conhecem os conceitos de depressão infantil. Torna-se necessário ficarem atentos a esses sintomas.

Nota-se falta de conhecimento de alguns pais quando $17 \%$ optaram pela resposta de que a depressão é uma doença mental. A literatura não trata a depressão como doença mental.

Segundo Cruvinel e Boruchovitch (2003) a falta de informações de pais e professores sobre a depressão infantil pode contribuir para aumentar as dificuldades dos alunos e causar inúmeras sequelas emocionais no futuro.

Perguntou-se aos respondentes quais eram os sintomas da Depressão Infantil. O Gráfico 05 apresenta os resultados em percentuais. 


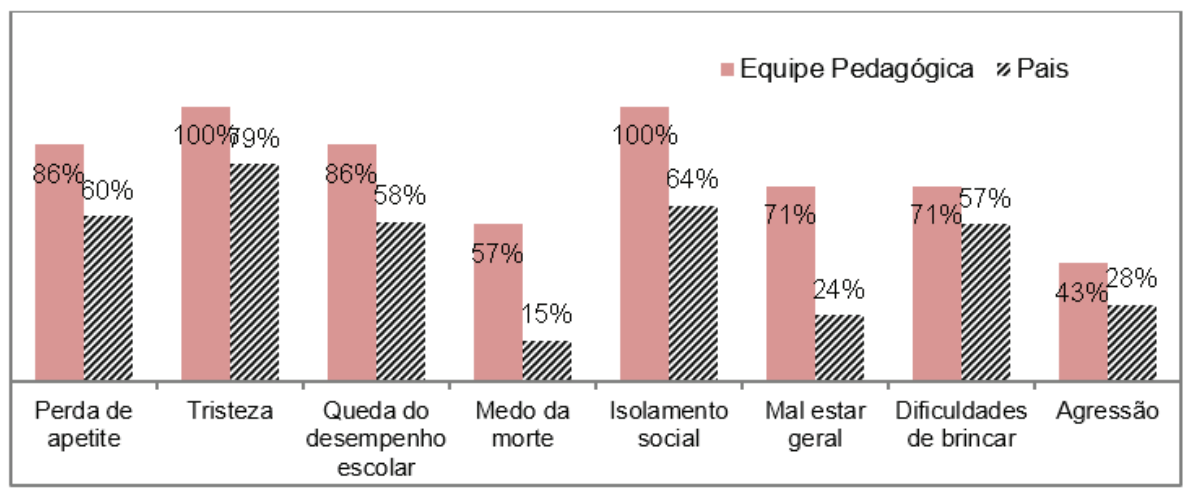

Gráfico 5. Opinião dos respondentes quanto aos sintomas da Depressão Infantil Fonte: Dados da pesquisa, 2015.

Nota-se que tristeza e isolamento social foram os sintomas mais percebidos pelos pais e equipe pedagógica, seguidos de perda de apetite e queda no desempenho escolar.

Feighner, Robins e Guze (1972) descrevem que os sintomas da depressão infantil são: humor deprimido e baixa estima, agressividade ou agitação, transtorno do sono, baixo rendimento escolar, diminuição da socialização (isolamento), dores no corpo, diminuição da energia, mudanças de apetite e peso.

Considerando os ensinamentos de Feighner, Robins e Guze, a pesquisa demonstra que a equipe pedagógica e os pais conhecem os sintomas da Depressão.

Foi perguntado aos respondentes o que originava a Depressão nas crianças. O Gráfico 06 mostra os resultados obtidos: 


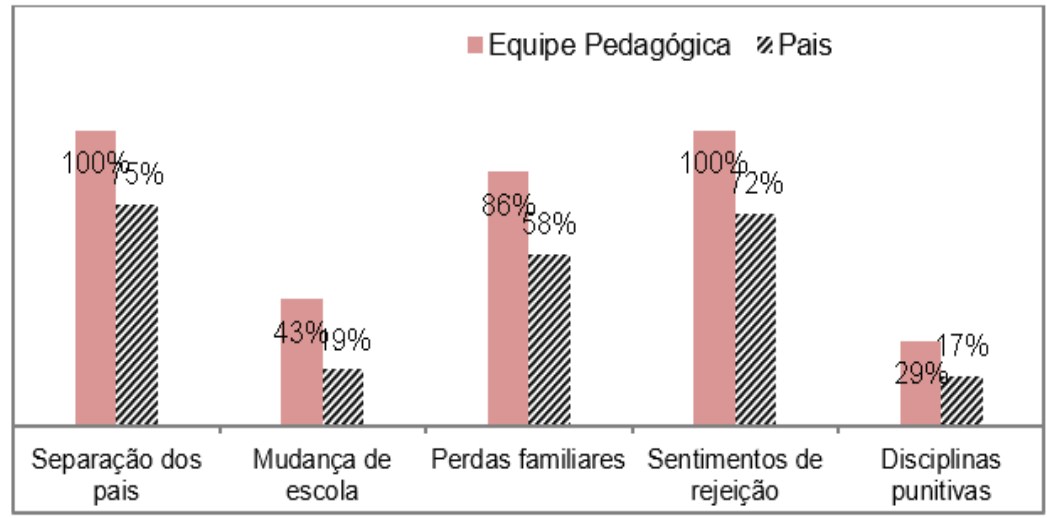

Gráfico 6. Opinião dos respondentes sobre a origem da Depressão Infantil Fonte: Dados da pesquisa, 2015.

Observou-se que separação dos pais e sentimentos de rejeição são os sintomas que contribuem para a origem da depressão na opinião dos respondentes.

Baptista e Assumpção (1999) assinalam que, frequentemente, crianças depressivas surgem de ambientes familiares caracterizados por atitudes de hostilidade, excesso de críticas e rejeições, onde presenciam conflitos conjugais e agressividade entre o casal.

Isso demonstra que a opinião dos respondentes está em conformidade com os pensamentos dos autores acima.

Foi perguntado aos pais e à equipe pedagógica em que ambiente poderia se detectar a depressão nas crianças. Notou-se que $100 \%$ da equipe pedagógica responderam que a depressão é detectada nas crianças no meio escolar e $81 \%$ dos pais responderam que é no meio familiar.

A resposta dos pais e da equipe pedagógica está de acordo com a literatura, pois a depressão pode ser detectada na criança tanto no meio familiar quanto no meio escolar.

Questionou-se quem deveria ajudar a criança com sintomas depressivos, e observou-se que $100 \%$ da equipe pedagógica e $81 \%$ dos pais responderam que são os profissionais especializados que deverão ajudar as crianças com sintomatologia depressiva.

Percebeu-se que as respostas dos pais e da equipe pedagógica são seme- 
lhantes e estão de acordo com o que a literatura apresenta, as crianças devem ser encaminhadas a profissionais especializados para tratamento da depressão.

Foi questionado sobre o que fazer com as crianças diagnosticadas com Depressão. O Gráfico 07 mostra os resultados obtidos em percentuais:

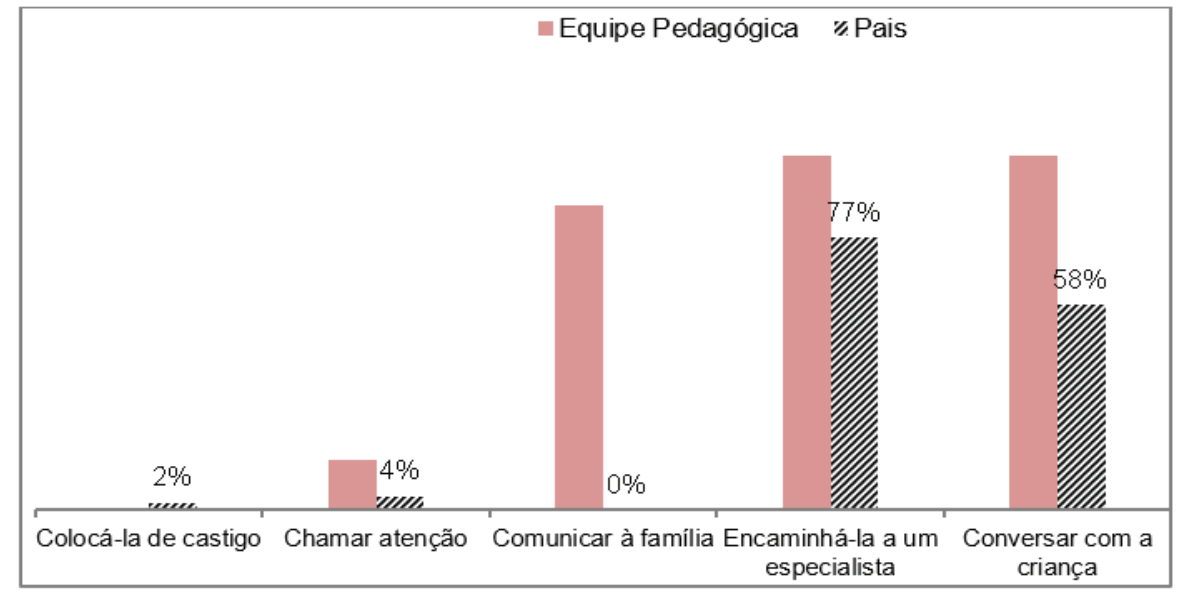

Gráfico 7. O que fazer com a criança diagnosticada com Depressão? Fonte: Dados da pesquisa, 2015.

Percebe-se que $100 \%$ da equipe pedagógica e $77 \%$ dos pais responderam que ao serem diagnosticadas com Depressão as crianças devem ser encaminhadas a um profissional especializado.

Observa-se a necessidade de se conhecer os sintomas depressivos, para que as crianças não saiam prejudicadas e iniciem o tratamento o quanto antes. E nota-se nesta pesquisa que os pais e a equipe pedagógica concordam que tão logo sejam diagnosticadas, as crianças devem ser direcionadas para especialistas.

A equipe pedagógica se demonstra em vários momentos preparada para identificar as crianças que apresentam sintomas depressivos. E, nesta questão especificamente, um total de $86 \%$ destes; entendem que devem comunicar à família para que o tratamento seja realizado.

Perguntou-se aos pais se eles tinham algum filho diagnosticado com depressão e à equipe pedagógica foi perguntado se já haviam trabalhado com crianças depressivas. Um total de $43 \%$ da equipe pedagógica já trabalhou com crianças diagnosticadas com depressão e $04 \%$ dos pais têm filho que foi diagnosticado com depressão. 
Perguntou-se à equipe pedagógica o que foi feito com as crianças diagnosticadas com Depressão e $100 \%$ falaram com os pais e depois encaminharam a criança para um atendimento psicológico (67\%).

Perguntou-se aos pais o que foi feito com as crianças diagnosticadas com Depressão e $50 \%$ dos pais levaram o filho ao psicólogo e outros $50 \%$ não tomaram nenhuma providência quanto ao tratamento.

Para Soares (2003) a depressão se agrava quando não há tratamento, ou quando os pais desconhecem o transtorno.

Observa-se que um dos pais não tratou o transtorno do filho, o que não está atendendo o que a literatura propõe podendo agravar o quadro clínico da criança.

Não foi possível identificar os motivos que levaram os pais a esta decisão, mas vale destacar aqui a importância do tratamento da depressão infantil.

\section{CONSIDERAÇÕES FINAIS}

Percebeu-se através dos dados coletados que a equipe pedagógica da escola, bem como os pais dos alunos, não apresentam dificuldades em lidar com a depressão infantil, tendo em vista que a maioria destes apresentam conhecimentos acerca do assunto, sabem identificar os sintomas da depressão infantil e quando as crianças são diagnosticadas com sintomas depressivos, os pais e educadores que são leigos no assunto- encaminham essas crianças a profissionais especializados.

Em relação ao conhecimento da equipe pedagógica e dos pais sobre o tema, notou-se que a maioria dos respondentes compreende o que é Depressão Infantil, portanto uma minoria significante; ainda não tem conhecimento sobre o assunto.

A fim de responder ainda se existem sintomas de Depressão nas crianças do $1^{\mathrm{o}}$ ao $3^{\mathrm{o}}$ ano, foram analisados alguns critérios considerados na literatura. Portanto observou-se que poucas crianças apresentaram sintomas do transtorno, sintomas como opinião depreciativa de si mesmas, isolamento, cansaço, péssima qualidade do sono e relacionamento familiar conturbado foram os mais notados. Quanto a esse resultado, é necessário que pais e educadores fiquem alertas e observem de perto o comportamento dessas crianças.

Considerando a gravidade do problema que foi exposto na pesquisa, a 
E.E.E.F.M Henrique Coutinho prioriza pouco palestras, debates e trocas de informações de pais e educadores sobre o assunto, deixando assim de contribuir com o crescimento educacional das crianças e retendo informações importantes sobre a Depressão Infantil.

\section{REFERÊNCIAS}

ANJOS, V.M.S.; FONSECA, R.C. Aspectos do relacionamento familiar que causam depressão infantil: Concepção dos psicoterapeutas que atuam na cidade de Belém-PA. 2002. 78f. Monografia (Graduação) - Universidade da Amazônia, Belém (PA), 2002.

ASSUMPÇÃO JÚNIOR (Org.) Psiquiatria da infância e da adolescência: casos clínicos. Porto Alegre: Artmed, 2014.

BAHLS, S.C. A depressão em crianças e o seu tratamento. São Paulo: Lemos, 2004.

BALLONE, G.J. Depressão na Infância. 2004. Disponível em: < http://www.psiqweb.med.br/geriat>. Acesso em: 07 out. 2015.

BAPTISTA, M.N.; ASSUMPÇÃO, F.B. Depressão na adolescência: Uma visão multifatorial. São Paulo: EPU, 1999.

BAUER, A.D. Sintomatologia depressiva infanto-juvenil: aspectos psicológicos e relações com o desempenho acadêmico Bauer. 2007. 182f. Dissertação (Mestrado em Educação) - Universidade Federal do Paraná, Curitiba, 2007.

CALDERANO, R.S.S.; CARVALHO, C.V. Depressão na Infância: um estudo exploratório. Psicologia em estudo. Ano 10, 181-189, 2005. Disponível em: <http://www. scielo.br/pdf/pe/v10n2/v10n2a04.pdf>. Acesso em: 10. dez. 2017.

CASTRO NETO, A. As crianças que sofrem caladas. Porto Alegre, 2002. Disponível em: < http://www.brasilrotario.com.br/revista/materiais/rev946/e946_p20.html>. Acesso em: 01 nov. 2015. 
COHEN, D.; MARCELLI, D. Infância e Psicopatologia. Porto Alegre: Artmed, 2009.

CRUVINEL, M.; BORUCHOVITCH, E. Depressão Infantil: uma contribuição para prática educacional. Revista Semestral da Associação Brasileira de Psicologia Escolar e Educacional, v. 7, n. 1, p. 77-84, 2003.

CRUVINEL, M.; BORUCHOVITCH, E. Sintomas depressivos, estratégias de aprendizagem e rendimento escolar de alunos do ensino fundamental. Psicologia em Estudo, v. 9, n. 3, p. 369-379, 2004.

CRUVINEL, M. Depressão infantil, rendimento escolar e estratégias de aprendizagem em alunos do ensino fundamental. 2003. 143f. Dissertação (Mestrado em Educação) - Universidade Estadual de Campinas (UNICAMP), Campinas, 2003.

FEIGHNER, J. P.; ROBINS, E.; GUZE, S. Diagnostic criteria for use in psychiatric research. Arch Gen Psychiatry, v. 26, p. 57-63, 1972.

FIERRO, A. Personalidade e aprendizagem no contexto escolar. In: PSICOLOGIA da Educação. Porto Alegre: Artes Médicas, 1996.

FONSECA, A. C. et al. Problemas emocionais nos alunos do ensino básico: frequência, características e evolução. Revista Portuguesa de Pedagogia, v. 32, n. 2, p. 163-186, 1988.

HOLMES, D. S. Psicologia dos transtornos mentais. Porto Alegre: Artmed, 1997.

LAFER, B. et al. Depressão no ciclo da vida. Porto Alegre: Artmed, 2000.

HUTTEL, J. et al. A depressão infantil e suas formas de manifestação. Psicol. Argum. Curitiba, jan./mar. 2011. Disponível em: <www2.pucpr.br/reol/index.php/PA/pdf/?dd1 $=4522>$. Acesso em: 21 abr. 2018.

LIBANÊO, J.C. Pedagogia e pedagogos: inquietações e buscas. Educar, Curitiba, n. 17, 2001. Disponível em: <http://www.ucs.br/etc/conferencias/index.php/anpedsul/9anpedsul/paper/view/525/640 > . Acesso em: 02 mar. 2017. 
LIMA, M.E.A.C.; GARCIA, D.F.; FIGUEIREDO, R.M.E. Depressão Infantil: um estudo em escolas da periferia de Belém. Belém: Eduefpa, 2005.

LIVINGSTON, R. Depressive Illness and learning difficulties: Research needs and Practical Implications. Journal of Leaning Disabilities, v. 18, n. 9, p. 518-520, 1985.

LOIOLA, A. Depressão infantil. Belo Horizonte, 2009. Disponível em: < http://www. webartigos.com/artigos/depressao-infantil/3798/\#ixzz1E2vPcrbn $>$. Acesso em: $07 \mathrm{dez}$. 2017.

MAJ, M.; SARTORIUS, N. Transtornos Depressivos. Porto Alegre: Artmed, 2005.

MARCONI, M.A.; LAKATOS, E.M. Técnicas de pesquisa: planejamento e execução de pesquisas, Amostragem e técnicas de pesquisa, elaboração, análise e interpretação de dados. 5. ed. São Paulo: Atlas, 2002.

MARCONI, M.A.; LAKATOS, E.M. Fundamentos de metodologia científica. 5. ed. São Paulo: Atlas, 2003.

MILLER, J.A. O livro de referência para a depressão infantil. São Paulo: MBooks do Brasil, 2003.

NUNES, A.S.; AZAMBUJA, G. de. Depressão Infantil: Informações sobre o distúrbio ajudam o docente no fazer pedagógico. Revista do Professor, v. 80, n. 20, p. 41-45, 2004.

OLIVEIRA, S.L. Tratado de metodologia científica: Projetos de Pesquisas, TGI, TCC, Monografias, Dissertação e Teses. 2. ed. São Paulo: Pioneira Thomson, 2002.

SCIVOLETTO, S.; TARELHO, L.G. Depressão na infância e na adolescência. Revista Brasileira de Medicina, v. 59, n. 8, p. 555-557, 2002.

SOARES, M.U. Estudos das Variáveis do Desenvolvimento infantil em crianças com e sem o diagnóstico de depressão. Rio Grande do Sul: Universidade Federal de Santa Maria, 2003. 
SOMMERHALDER, A.; STELA, F. Depressão na infância e o papel do professor. Revista de Neuropsiquiatria, v. 59, n. 1, p. 200, 2001.

STRECK, D.R. Rousseau e a educação. Belo Horizonte: Autêntica, 2004.

TIBA, I. Quem ama, educa: formando cidadãos éticos. São Paulo: Integrare, 2012.

Recebido em: 15/03/2018 Aceito em: 16/04/2018 